\title{
XXXVII. The use of the potentiometer on alternate current circuits
}

\section{Charles V. Drysdale D.Sc.}

To cite this article: Charles V. Drysdale D.Sc. (1909) XXXVII. The use of the potentiometer on alternate current circuits, Philosophical Magazine Series 6, 17:99, 402-411, DOI:

$10.1080 / 14786440308636616$

To link to this article: http://dx.doi.org/10.1080/14786440308636616

册 Published online: 21 Apr 2009.

Submit your article to this journal $\sqsubset \pi$

Џ Article views: 2

Q View related articles $\square$

Citing articles: 5 View citing articles 5 
these figures. It will be noted that where the value of $n$ is: less than about $1 \cdot 38, \mathrm{~K}$ increases with an increase in temperature, while for greater values of $n, \mathrm{~K}$ decreases as the temperature increases.

Fing. 3.

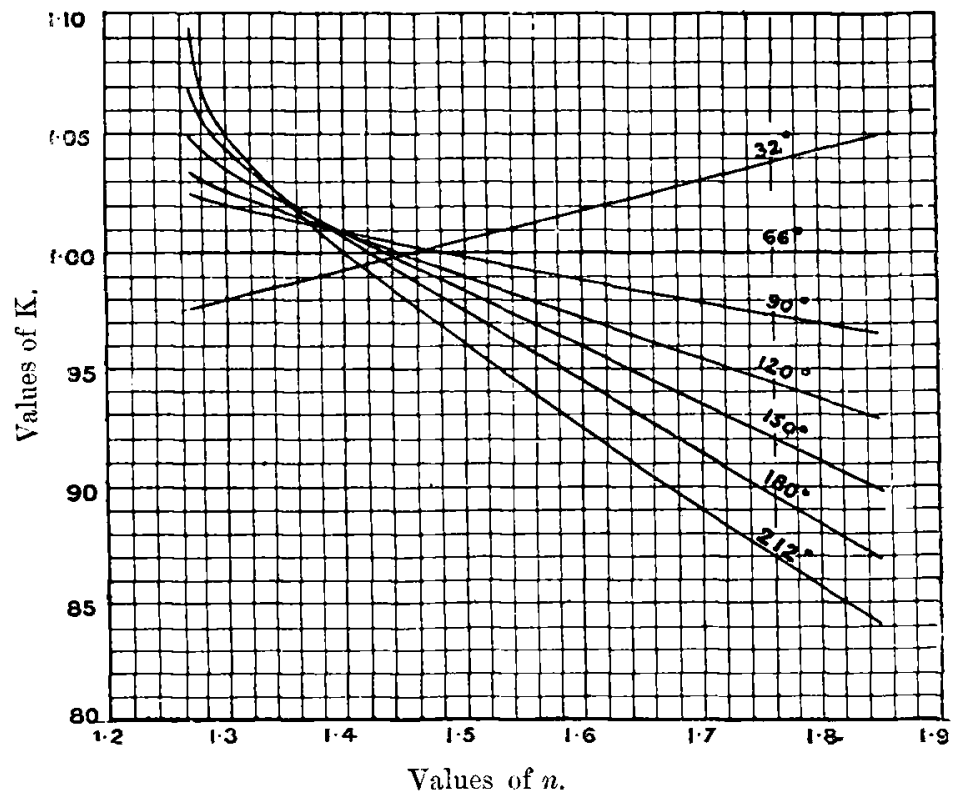

The variation of $\mathrm{K}$ with temperature becomes grenter as $n$ increases or diminishes from 1:38.

Thus when $n=1.80$ (its mean value for a wrought-iron pipe), the mean variation in $\mathrm{K}$ is approximately 1 per cent. per $10^{\circ} \mathrm{F}$. temperature variation. This rate of variation of $\mathbf{K}$ with temperature decreases as the temperature increases.

The University, Manchester.

XXXVII. The Use of the Potentiometer on Alternate Current Circuits. By Charles V. Drysdale, D.Sc.*

$\mathrm{NE}^{\mathrm{NE}}$ of the greatest inconveniences in connexion with alternate current measurements has always been the question of range. Owing to the fact that all instruments employed for direct indication of alternate currents or P.Ds. have a square law, their range is small and they become impracticably delicate when low voltages are concerned. There is therefore a very great need for some instrument which, like the direct-current potentiometer, should be

* Communicated by the Physical Society : read January 22, 1903. 
capable of measuring P.Ds. and currents of any range with accuracy. It would also be a great convenience if this instrument were capable of indicating the phase as well as the magnitude of the P.D. or current tested.

In attempting to apply the potentiometer principle to alternate current measurements, two processes seem to be possible- $(a)$ the balancing of the alternate current P.D. against an equal direct current P.D. by the employment of some differential balancing device preferably of an electrostatic character, or (l) the balaneing of two alternate current P.Ds. against one another. Such propositions as have hitherto been made for an alternate-current potentiometer have, the writer believes, always been based on the former idea, owing to the fact that the latter principle would involve equality of phase as well as of P.D. in the two voltages compared. He understands that some time ago Mr. Swinburne suggested the use of a differential electrometer in Fig. 1.

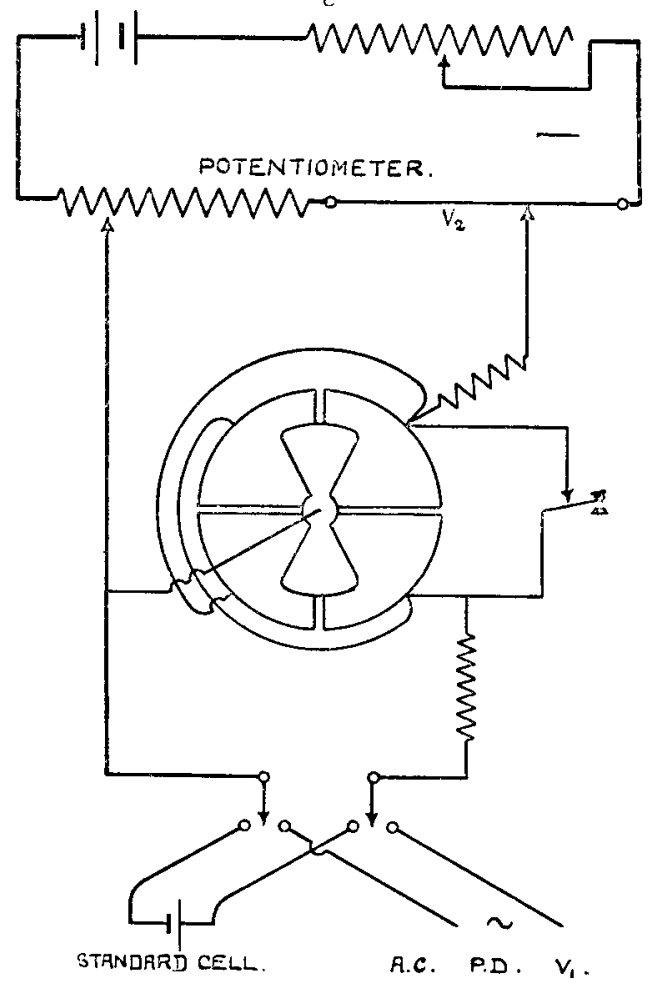

connexion with a potentiometer, but has not seen any details. An obrious device would be that shown in fig. 1, 
in which the P.D. to be measured is applied between the needle and one pair of quadrants, while that derived from the potentiometer is connected between the needle and the other pair of quadrants, in each case through a considerable resistance, say one megohm. By connecting a key to the opposite pairs of quadrants, which normally short-circuits them, but disconnects them when depressed, a deflexion should be obtained to right or left proportional to $\mathrm{V}_{1}{ }^{2}-\mathrm{V}_{2}{ }^{2}$ or $2 \mathrm{VdV}$ when balance is nearly obtained. Any want of symmetry in the electrometer should be eliminated by connecting the standard cell as shown, so as to obtain a double weighing method.

The procedure in this case is very simple, and exactly resembles ordinary direct-current potentiometry. The scole difficulty lies in the electrometer. It should be possible by multicellular devices, or otherwise, to obtain a lair amount of sensitiveness with 1 or $1 \frac{1}{2}$ volts, the P.D. of the standard cell, as has been done by $\mathrm{Mr}$. Addenbrooke, but when we come to a tenth of a volt or less, as is so often necessary in current measurement, electrostatic devices seem hopeless. All other magnetic or thermal devices are incorrect in principle as requiring an appreciable current to operate them, which militates against the accuracy of the potentiometer; but by employing a low-resistance potentiometer, and a differential thermal device, such as could be made from the Duddell thermo-galvanometer employing two junctions and two heaters, or two crossed thermo-junctions in series, a sufficiently sensitive and accurate potentiometer could perhaps be made.

In view of the difficulty of making such devices, however, the writer has turned his attention to the second method, i.e. of balancing the alternate current P.D. to be measured against a known alternate current P.I., by the interposition of a sensitive alternate-current detector, such as a telephone or vibration galvanometer. This of course implies that the two voltages under comparison must have the same magnitude, frequency, and phase, and, approximately, the same waveform*.

The equality of frequency is of course secured by deriving the test and comparison voltages from the same source of supply, but some special device is needed for bringing the phases into coincidence. In some experiments recently

* Since this was written the writer has been informed that Dr. Sumpner has somewhere suggested that an alternating-current potentiometer could be made, if any means were available for bringing the phase of the current in the slide-wire into coincidence with that of the P.D. to be measured. 
made with the writer's phase-shifting transformer, however *, the accuracy of the phase-variation was found to be so good that it was thought worth while to introduce it into potentiometer work; and fig. 2 shows the diagram of the connexions

Fig. 2.

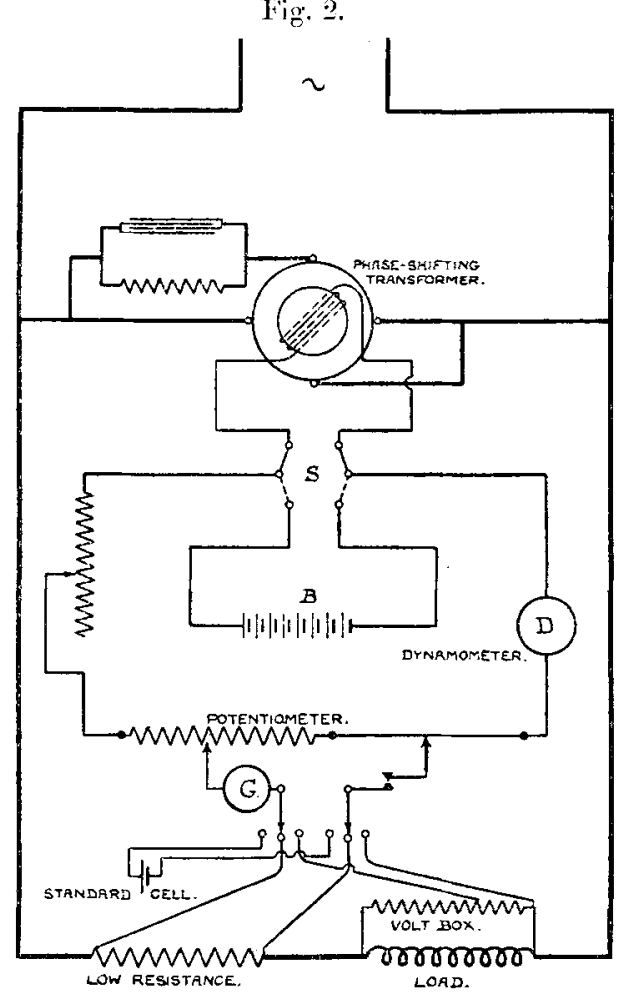

which have been employed. The phase-shifter is here shown supplied with single phase current through a phase-splitting device, which can be built up with it so that it merely requires connecting straight on to the mains. The current derived from the secondary of this transformer traverses the rhoostat coils, and slide-wire of an ordinary potentioneter, such as the Crompton form; and also some form of dynamometer-current measuring device. The writer has found a Weston A.C. voltmeter excellent for this purpose, as it gives a very good reading with the current ( 05 ampere) employed with the Crompton potentiometer. The remainder of the potentiometer is connected up precisely as for ordinary

* 'Electrician,' Dec. 11, 1908. 
direct current working, except that a vibration galvanometer is substituted for the ordinary form. By having an auxiliary battery $B$ and throw-over switch $S$, the arrangement is always ready for either direct-current or alternate-current comparisons.

The procedure is then as follows:-The throw-over switch is first arranged to supply direct current from the battery $B$, and the rheostat altered until the standard cell is balanced at its nominal value, as in ordinary direct-current working. The dynamometer reading is then carefully noted, or a fiducial mark is made, which always represents the exact -05 ampere. On now throwing over to alternate current, the rheostat is altered to reproduce the same R.M.S. current as indicated by the dynamometer $\mathrm{D}$; and the position of the potentiometer contact is shifted and the phase-shifter turned, until the vibration galvanometer shows no vibration. The adjustment is very similar to that of the two resistances in an Anderson's bridge, and presents no difficulties. The voltage and phase are then read off on the potentiometer and phaseshifter respectively. In the illustration a low resistance is connected in series with the load, and a volt-box in parallel with it, and the current and P.I). can be determined directly in the ordinary way. Of course the phase-shifting transformer must always be connected to the same source of supply as the loud.

Instead of the vibration galvanometer, a dynamometer or electrometer in which one pair of terminals is connected to the supply so as to be "soparately excited," and the other to the ordinary galvanometer terminals, has been employed with good results. The deflexions are then to left or to right as in an ordinary galvanometer. But it must not be forgotten in this case that balance will be obtained not only when the rectors of the two P.Ds. compared are coincident, but also when their vector difference is in quadrature with the P.D. of the supply. For this purpose, if such an instrument is used it must have its "exciting terminals" changed over from one phase to the other, and balance secured in both cases.

Before giving examples of readings obtained in this manner, we must consider what is really measured. It is obvious that this device does not indicate the effective or R.M.S. value of the P.D., except when the supply and tested wave-forms are both sinusoidal or of identical form. When a vibration galvanometer is employed, its sensitiveness to the fundamental wave is so great in comparison with that to the harmonics, that we shall be practically correct in assuming 
that it is the fundamental wave only which is measured, and the comparison is really between the mean and not the R.M.S. values. On the other hand, if there is any serious difference of wave-form, the sensitireness to the ripper harmonics should be sufficient to prevent an exact balance being secured, and this warns us when great accuracy is not to be expected.

The effective value of an irregular periodic roltage is

$$
\overline{\mathrm{V}}=\sqrt{\mathrm{\Sigma}} \overline{\mathrm{V}}_{n}{ }^{2}
$$

where $\bar{\nabla}_{n}$ is the effective value of the harmonic of order $n$. If the sum of the squares of the higher harmonics is small in comparison with the square of the fundamental, we may take the approximate square root, and

$$
\text { or } \quad \begin{aligned}
\overline{\mathrm{V}} & =\overline{\mathrm{V}}_{1}+\frac{1}{2 \overline{\mathrm{V}}_{1}} \Sigma \mathrm{V}_{n}{ }^{2}, \\
\overline{\mathrm{V}} & =\overline{\mathrm{V}}_{1}\left\{1+\frac{1}{2 \mathrm{~V}_{\mathrm{l}}{ }^{2}} \Sigma \mathrm{V}_{n}{ }^{2}\right\},
\end{aligned}
$$

where $\Sigma \bar{V}_{n}{ }^{2}$ in the last two expressions implies the sum of the squares of the effective values of all the harmonics, excluding the fundamental.

In the case of a single harmonic this becomes

$$
\bar{V}=\bar{V}_{1}\left\{1+\frac{1}{2}\left(\frac{\bar{V}_{n}}{V_{1}}\right)^{2}\right\},
$$

and the expression in brackets only differs 1 per cent. from unity when $\bar{V}_{n}$ is 14 per cent. of $\bar{V}_{1}$. Such a difference should be fairly easily recognizable, and would probably be sufficient to prevent the obtaining of a perfect balance on the vibration galvanometer ; and, moreover, if the distortion of wave-shape is great, there is little object, as a rule, in great accuracy of measurement. If accuracy is required in such cases, it can of course be secured by tracing the wave-shape and making the above correction, but if care is taken to have a supply of fairly sinusoidal wave-form, the measurements may be considered sufficiently accurate for the majority of purposes. It should be observed that this difficulty, or a similar one, is inseparable from any method which can be devised, in which the detector is employed to indicate the difference between the test and potentiometer P.Ds. as is done with direct currents.

Measurements.-'Two illustrations will be sufficient to show 
the possibilities of the method. An ordinary Crompton potentiometer was used with a Weston dymamometer voltmeter in series with it, and the connexions were made as in fig. 3. A Rubens vibration galvanometer was at first used,

Fìg. 3.

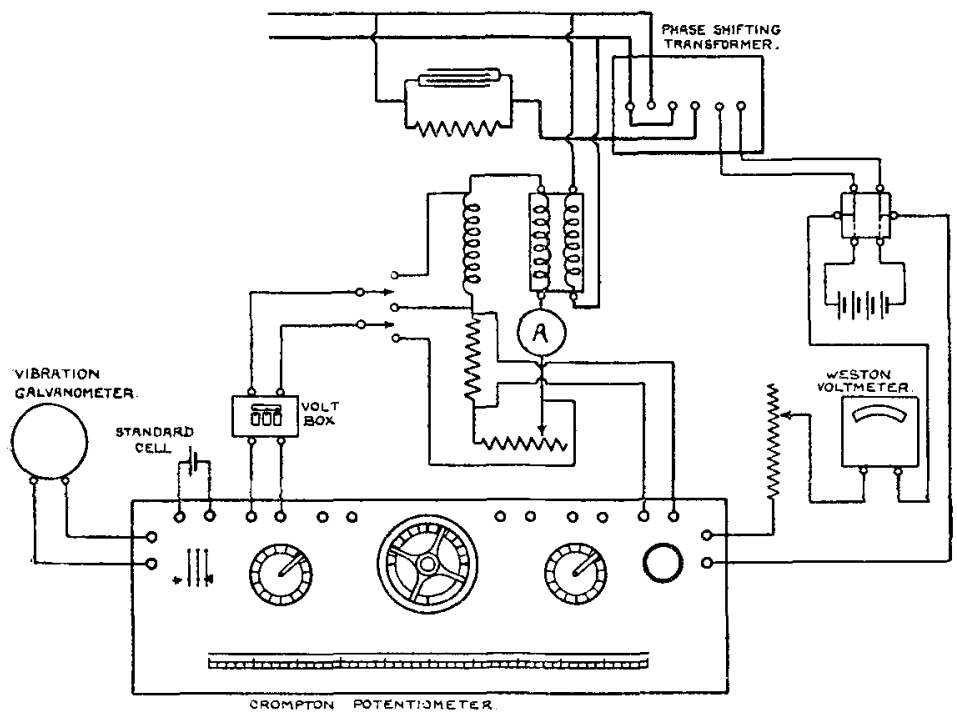

but was replaced by a Campbell bifilar instrument, which was found much more sensitive and convenient. A check with direct current and a Cadmium cell showed that the normal current was obtained when the dynamometer indicated 82 "volts," and this reading was reproduced in all the alternate-current measurements.

The first test was a comparison of the readings of a Kelvin Deka-ampere-balance, with the current as given by the P.D. across a Crompton $\cdot 04 \omega$ manganin resistance. The following results were obtained :-

\begin{tabular}{|c|c|c|}
\hline $\begin{array}{c}\text { Current by } \\
\text { Kelvin. }\end{array}$ & $\begin{array}{c}\text { P.D. by } \\
\text { Potentionieter. }\end{array}$ & $\begin{array}{c}\text { Current by } \\
\text { Potentiometer. }\end{array}$ \\
\hline 25 & 1.002 & 25.05 \\
20 & 8018 & 20045 \\
15 & 6029 & 15055 \\
\hline
\end{tabular}

Frequency of supply $72 \sim$. 
The readings were obtained with great ease and definiteness, half a division on the slide-wire, or .0005 volt, being easily detected, in spite of the fact that trouble was found from mechanical vibration, as the alternator was in the same room. There seems no reason to doubt that 0002 volt could be easily detected, or that a drop of $\cdot 1$ volt could be measured to an accuracy of 2 per cent. or closer. The readings of the phase angle repeated themselves constantly to within $\cdot 1$ degree.

To give some idea of the accuracy of phase measurements, a resistance and ironless choking-coil were connected in series with the $\cdot 04 \omega$ resistance, and an alternating current of 15 amps. at $60 \sim$ passed through the combination. lieadings were then talien of the P.D. across the $\cdot 04 \omega$ resistance, across the choking-coil, total resistance, and the whole circuit, the last three being taken by the aid of a $10 \times 1$ volt box. The following are the results :-

\begin{tabular}{|c|c|c|c|c|}
\hline \multirow{2}{*}{ Cireuit. } & \multicolumn{2}{|c|}{ First Test. } & \multicolumn{2}{|c|}{ Second Test. } \\
\hline & P.D. & $\begin{array}{c}\text { Phase-angle, } \\
\text { degrees. }\end{array}$ & P.D. & $\begin{array}{l}\text { Phase- } \\
\text { angle. }\end{array}$ \\
\hline .04 resistance $\quad .$. & 5960 & 465 & $\ldots \ldots$ & $\ldots \ldots$ \\
\hline Total resistunce & $3 \cdot 117$ & $47 \cdot 1$ & $3 \cdot 108$ & $47 \cdot 3$ \\
\hline Choking-coil ...... & 4880 & 1259 & $4 \cdot 928$ & 125 \\
\hline Mains $\quad . . . . . . .$. & $6 \cdot 185$ & 953 & $6 \cdot 218$ & $94 \cdot 9$ \\
\hline
\end{tabular}

The difference between the first and second readings is due to the fact that a carbon resistance was employed which became heated.

Fig. 4 (p. 410) is a graphical representation of the result in the last case, the horizontal line representing the resistance drop, and the other two lines the drop across the choking-coil and whole circuit respectively. Although the triangle does not quite close, the result may be taken as satisfactory in consideration of the fact that single phase supply was used in this case, and the phase was split by condensers. It should be noted also that errors in the phase angle do not in any way affect the accuracy of the magnitudes of the P.Ds.

The writer has designed a potentiometer in which a small phase-shifting transformer and dynamometer are included in 
the case, with a throw-over switch, permitting the instrument to be used as either a direct or alternate current potentiometer.

Fig. 4.

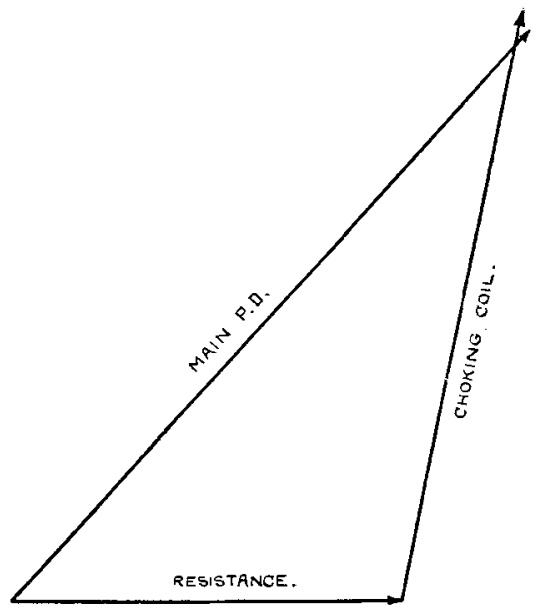

Fig. 5 shows the connexions, which need little explanation. The main circuit of the potentiometer, consisting of the rheostats $R_{1}$ and $R_{2}$, the two dials $D_{1}$ and $D_{2}$, the slide-wire $\mathrm{W}$, and the dynamometer $\mathrm{D}$, is connected to two of the blocks of the change-over switch $\mathrm{C}$, which is similar in form to the well-known selector switch used in the Crompton Potentiometer. The derived P.D. from the dial $D_{2}$ and slide-wire contact is led by the key $\mathrm{K}$ and the selector switch $\mathrm{S}$ to tin o more of the contacts on C. The remaining eight contacts on C are connected in pairs to the phase-shifting transformer $\mathrm{P}$, the battery terminals D.C., the ordinary galvanometer terminals $G$, and the vibration galvanometer terminals V.G. The phase-shifter primary is excited from the terminals A.C., which are here shown four in number, for two-phase or splitphase. A single motion of the switch $\mathrm{C}$ to right or left connects the main circuit of the potentiometer on to the battery or secondary of the transformer, and simultaneously connects the sliding contacts through the selector switch to the appropriate galvanometer. The key $\mathrm{K}$ being provided with a holding-down cam, leaves the hands free to move the potentiometer contacts and rotate the phase-shifter simultaneously. A frequency meter $\mathrm{F}$ of the vibrating reed type may be fixed on the base if desired, in which case the instrument is available for inductance and capacity measurements. 
